\title{
High Performance Vector Control of 3-Phase IM Drives under Open-Phase Fault Based on EKF for Rotor Flux Estimation
}

\author{
Mohammad Jannati*, Tole Sutikno**, Nik Rumzi Nik Idris*, Mohd Junaidi Abdul Aziz* \\ * UTM-PROTON Future Drive Laboratory, Faculty of Electrical Engineering, Universiti Teknologi Malaysia, \\ 81310 Skudai, Johor Bahru, Malaysia \\ ** Department of Electrical Engineering, Faculty of Industrial Technology, Universitas Ahmad Dahlan, \\ Yogyakarta 555164, Indonesia
}

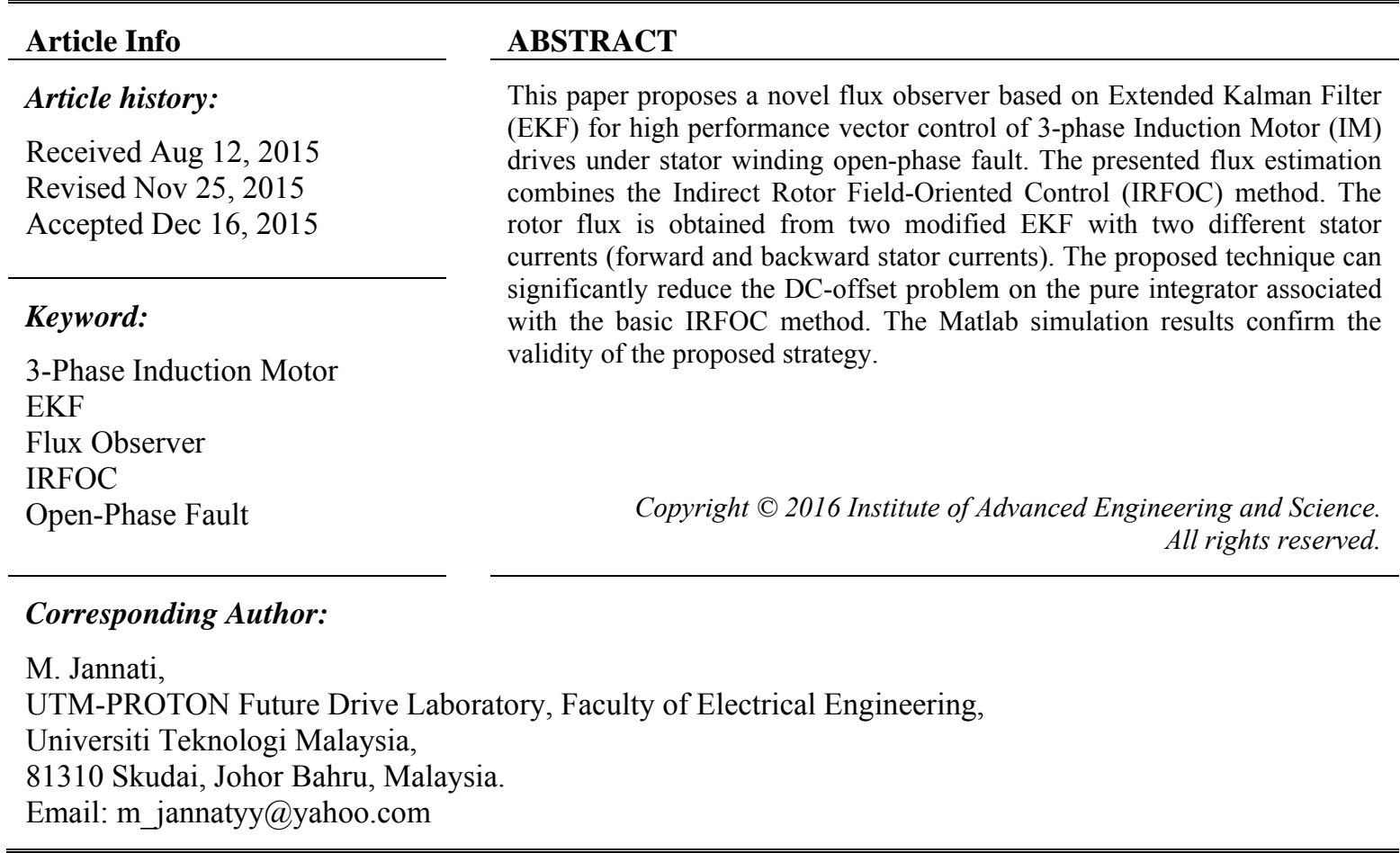

\section{INTRODUCTION}

Recently, 3-phase Induction Motors (IMs) have been extensively developed due to their low cost, high reliability and good performance. Field-Oriented Control (FOC) technique for 3-phase IM drives has drawn much interest among researchers due to its accuracy and superior dynamics. Generally, there are two possibilities for the FOC technique based on orientation of the rotating frame; they are: Rotor Field-Oriented Control (RFOC) and Stator Field-Oriented Control (SFOC). The way of flux position is calculated determines the type of FOC; Direct Field-Oriented Control (DFOC) and Indirect Field-Oriented Control (IFOC). The basic FOC strategies still have some drawbacks such as complexity and sensitivity to the motor parameter variations such as rotor and stator resistances. Moreover, the basic FOC algorithm cannot be used for some abnormal conditions in 3-phase IM drives. One of the most common types of abnormal conditions in 3-phase IM drives is open-phase fault [1]. By applying the basic FOC techniques to a faulted 3-phase IM (3-phase IM under stator winding open-phase fault), significant oscillations in the motor speed and torque output will be developed. To solve this problem, some modified vector control methods have been introduced to improve the performance of the 3-phase IM drives under open-phase fault [2]-[7].

The key issue of the IRFOC controlled 3-phase IM drives is the estimation of rotor flux. A most popular method to obtain the information of rotor flux in IRFOC method is using a pure integration. However, using a pure integration for the rotor flux estimation is sensitive to different kinds of problems such as DC-offset problem. To solve this problem, many researchers have addressed improvement on the 
estimation of rotor flux in 3-phase IM drives [8]-[14]. However, these methods cannot be used for faulty machine as these methods are designed based on healthy 3-phase IM equations.

In this paper, two modified Extended Kalman Filter (EKF) algorithms in order to rotor flux estimation are replaced the pure integrator. It is shown that the faulted machine stator currents in the rotating reference frame can be classified as forward and backward currents. Based on this simplicity to control faulty 3-phase IM, two modified IRFOC algorithms are used. These two currents (forward and backward currents) are used for estimation of the forward and backward rotor fluxes using EKF algorithm. The proposed method can significantly reduce the DC-offset problem on the pure integrator associated with the IRFOC of faulty 3phase IM drives. The simulation study is carried out with a $475 \mathrm{~W}$ star-connected 3-phase IM. The results confirm the effectiveness of the proposed flux observer when applied to the IRFOC of a faulty 3-phase IM drive. This paper is organized as follows: After introduction in section 1, in section 2, the d-q model of a faulty star-connected 3-phase IM is presented. Next, section 3 describes the development of the IRFOC algorithm for vector control of a faulted machine. The proposed method for rotor flux estimation of a faulty 3-phase IM is analyzed in section 4. The performance of the presented strategy is checked using Matlab/MFile software in section 5 and section 6 concludes the paper.

\section{FAULTY STAR-CONNECTED 3-PHASE IM MODEL}

The d-q model of star-connected 3-phase IM under open-phase fault in the stationary reference frame (superscript " $s$ ") can be shown by the following equations [5]:

$$
\begin{aligned}
& v_{d s}^{s}=r_{d s} i_{d s}^{s}+\frac{d \lambda_{d s}^{s}}{d t}, \quad v_{q s}^{s}=r_{q s} i_{q s}^{s}+\frac{d \lambda_{q s}^{s}}{d t} \\
& 0=r_{r} i_{d r}^{s}+\frac{d \lambda_{d r}^{s}}{d t}+\omega_{r} \lambda_{q r}^{s}, 0=r_{r} i_{q r}^{s}+\frac{d \lambda_{q r}^{s}}{d t}-\omega_{r} \lambda_{d r}^{s} \\
& \lambda_{d s}^{s}=L_{d s} i_{d s}^{s}+M_{d} i_{d r}^{s}, \quad \lambda_{q s}^{s}=L_{q s} i_{q s}^{s}+M_{q} i_{q r}^{s} \\
& \lambda_{d r}^{s}=M_{d} i_{d s}^{s}+L_{r} i_{d r}^{s}, \quad \lambda_{q r}^{s}=M_{q} i_{q s}^{s}+L_{r} i_{q r}^{s} \\
& \tau_{e}=\frac{P o l e}{2}\left(M_{q} i_{q s}^{s} i_{d r}^{s}-M_{d} i_{d s}^{s} i_{q r}^{s}\right) \\
& \frac{\text { Pole }}{2}\left(\tau_{e}-\tau_{l}\right)=J \frac{d \omega_{r}}{d t}+F \omega_{r}
\end{aligned}
$$

where, $v_{d s}^{s}$ and $v_{q s}^{s}$ are the stator d-q axes voltages, $i_{d s}^{s}, i_{q s}^{s}, i_{d r}^{s}$ and $i_{q r}^{s}$ are the stator and rotor d-q axes currents, $\lambda_{d s}^{s}, \lambda_{q s}^{s}, \lambda_{d r}^{s}$ and $\lambda_{q r}^{s}$ are the stator and rotor d-q axes fluxes. $L_{d s}, L_{q s}, L_{r}, M_{d}$ and $M_{q}$ indicate the stator and rotor $\mathrm{d}-\mathrm{q}$ axes self and mutual inductances. $r_{d s}, r_{q s}$ and $r_{r}$ are the stator and rotor d-q axes resistances. $\omega_{r}$ is the machine speed. $\tau_{e}$ and $\tau_{l}$ are electromagnetic torque and load torque. $J$ and $F$ are the moment of inertia and viscous friction coefficient respectively. Moreover, $r_{d s}=r_{q s}=r_{s}, L_{d s}=L_{l s}+3 / 2 L_{m s}$, $L_{q s}=L_{l s}+1 / 2 L_{m s}, M_{d}=3 / 2 L_{m s}$ and $M_{q}=\sqrt{ } 3 / 2 L_{m s}$ [5] ( $L_{l s}$ and $L_{m s}$ are leakage and mutual inductances respectively).

\section{VECTOR CONTROL OF A FAULTY STAR-CONNECTED 3-PHASE IM}

In this paper, a method to control faulty machine based on IRFOC is presented. In RFOC strategy it is necessary that the motor equations transfer to the rotating reference frame. For this purpose, the transformation matrix as shown in (2) is used [15]:

$$
\left[T_{s}^{e}\right]=\left[\begin{array}{cc}
\cos \theta_{e} & \sin \theta_{e} \\
-\sin \theta_{e} & \cos \theta_{e}
\end{array}\right]
$$

where, superscript " $e$ " indicates the equations are in the rotating reference frame (in this paper, " $\theta_{e}$ " is the angle between the stationary reference frame and rotating reference frame. Furthermore, " $\omega_{e}$ " is the angular 
velocity of the rotor field-oriented reference frame). Using equation (2), equation (1), can be obtained as (3)(7):

$$
\left[\begin{array}{c}
v_{d s}^{e} \\
v_{q s}^{e} \\
0 \\
0
\end{array}\right]=\left[\begin{array}{c}
v_{d s}^{+e} \\
v_{q s}^{+e} \\
v_{d r}^{+e} \\
v_{q v}^{+e}
\end{array}\right]+\left[\begin{array}{c}
v_{d s}^{-e} \\
v_{q s}^{-e} \\
v_{d r}^{-e} \\
v_{q v}^{-e}
\end{array}\right]
$$

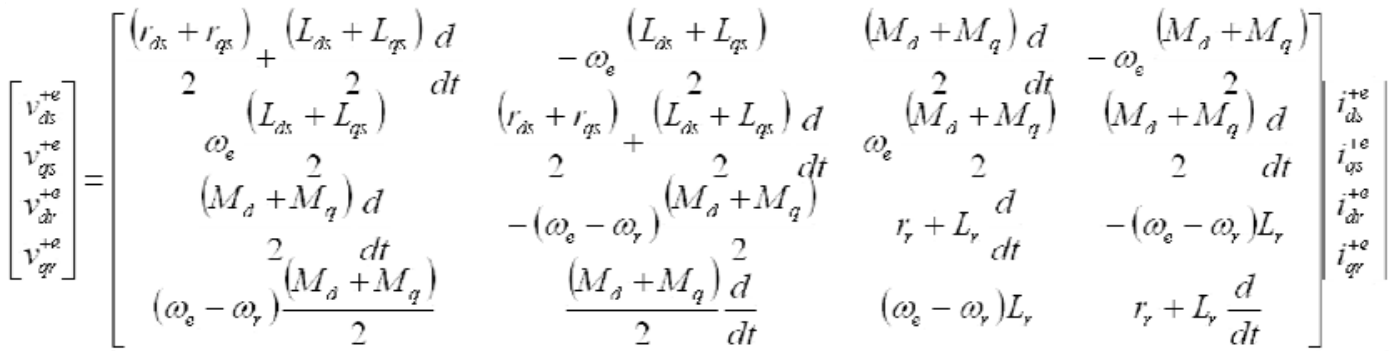

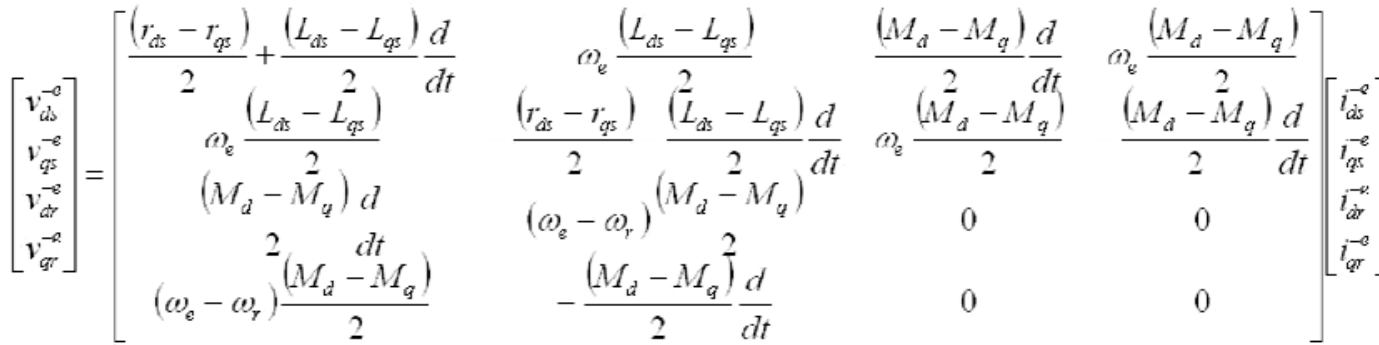

As can be seen, equation (3) includes two set of equations (the terms with superscript " $+e$ " and the terms with superscript "- $e$ "). Each term represents a healthy 3-phase IM equation. Consequently, vector control of a 3-phase IM under open-phase fault using two modified RFOC algorithms is possible. The block diagram of RFOC for a faulty motor is shown as Figure 1. In Figure 1, RFOC (1) is used to compensate the terms with superscript " $+e$ " and RFOC (2) is used to compensate the terms with superscript " $e$ ". 


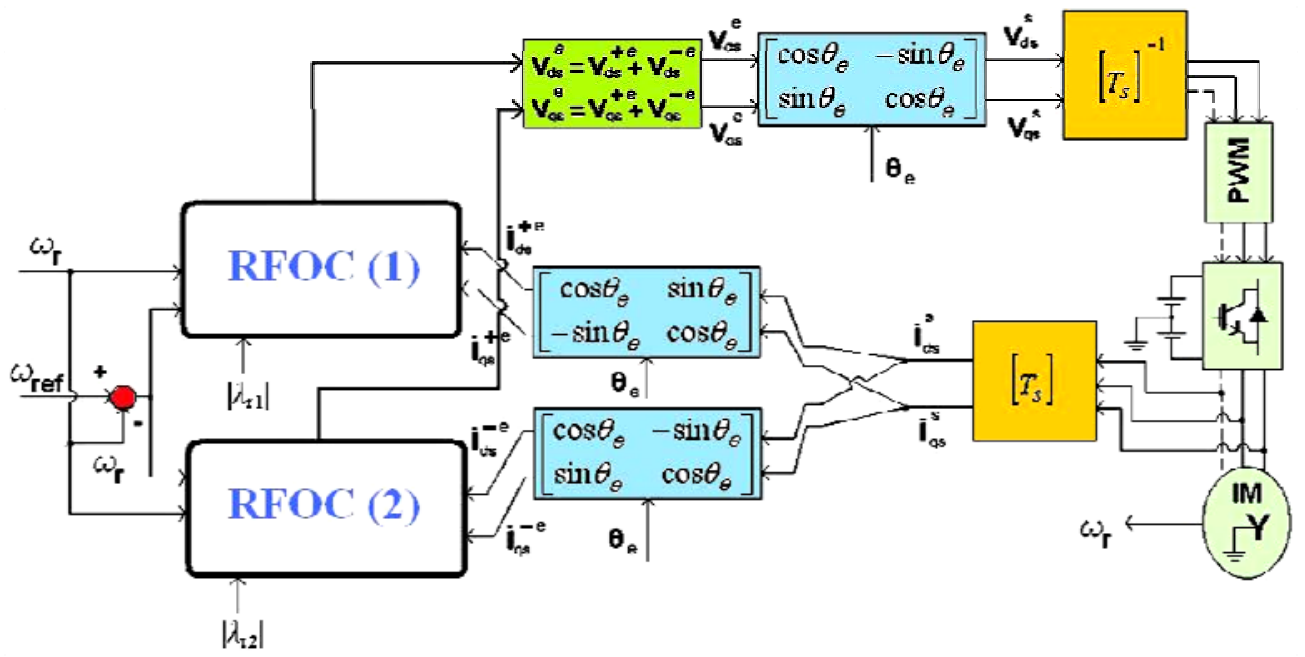

Figure 1. Block diagram of RFOC for a faulty motor

In Figure 1 [5]:

$$
\left[T_{s}\right]=\frac{\sqrt{2}}{2}\left[\begin{array}{cc}
1 & -1 \\
1 & 1
\end{array}\right]
$$

Notice that, Figure 1 can be used for healthy 3-phase IM as well. The necessary modifications which are needed in order to control healthy motor are as given in Table 1. Based on Figure 1 and Table 1, during normal condition, the output of RFOC (2) is zero. On the other hand, in normal condition the proposed scheme is the same as basic RFOC scheme.

Table 1 . The necessary modifications which are needed in order to control healthy motor in Figure 1

$r_{d s}=r_{q s}=r_{s} \quad, \quad M_{d}=M_{q}=M=\frac{3}{2} L_{m s} \quad, \quad L_{d s}=L_{q s}=L_{s}=L_{l s}+\frac{3}{2} L_{m s}$
$\left[T_{s}\right]=\sqrt{\frac{2}{3}}\left[\begin{array}{ccc}0 & -\frac{\sqrt{3}}{2} & \frac{\sqrt{3}}{2} \\ 1 & -\frac{1}{2} & -\frac{1}{2} \\ \frac{1}{\sqrt{2}} & \frac{1}{\sqrt{2}} & \frac{1}{\sqrt{2}}\end{array}\right]$

\section{ROTOR FLUX ESTIMATION OF A FAULTY STAR-CONNECTED 3-PHASE IM USING EKF}

In this work, two modified EKF algorithms are used to estimate the rotor fluxes in the RFOC (1) and RFOC (2). The EKF is an estimator which can be used for both linear and nonlinear systems. For the purpose of rotor fluxes estimation, the stator currents as well as rotor fluxes are chosen as the state variables. The state space model of an IM can be expressed in the form of equations (9) and (10):

$$
\begin{aligned}
& \dot{x}=A x+B u \\
& y=C x
\end{aligned}
$$

where $A, B$ and $C$ are the system matrix, input matrix and output matrix. $x, u$ and $y$ are the system state matrix, system input matrix and system output matrix. The matrices of $x, y$ and $u$ in equations (9) and (10) are given as follows: 


$$
\begin{aligned}
& x=\left[\begin{array}{llll}
i_{d s} & i_{q s} & \lambda_{d r} & \lambda_{q r}
\end{array}\right]^{T} \\
& y=\left[\begin{array}{ll}
i_{d s} & i_{q s}
\end{array}\right]^{T} \\
& u=\left[\begin{array}{ll}
v_{d s} & v_{q s}
\end{array}\right]^{T}
\end{aligned}
$$

Based on equation (4), the matrices of $A_{1}, B_{1}$ and $C_{1}$ in equations (9) and (10) are obtained as (14a)-(14c):

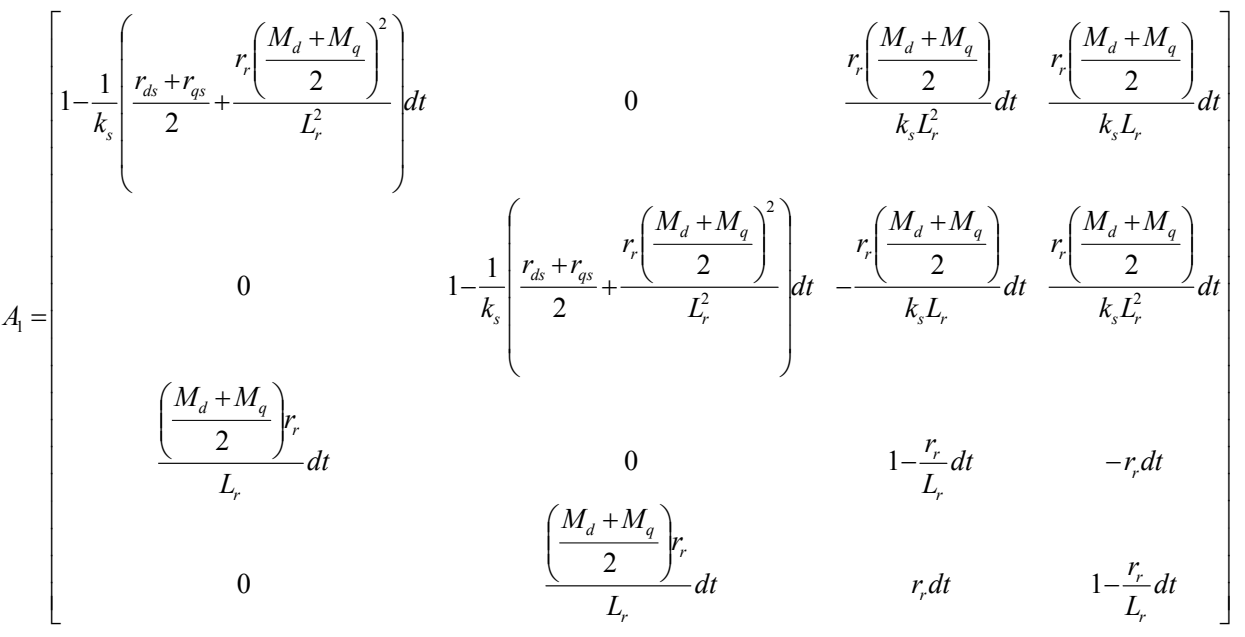

$$
\begin{aligned}
& B_{1}=\left[\begin{array}{cccc}
\frac{1}{k_{s}} d t & 0 & 0 & 0 \\
0 & \frac{1}{k_{s}} d t & 0 & 0
\end{array}\right]^{T} \\
& C_{1}=\left[\begin{array}{llll}
1 & 0 & 0 & 0 \\
0 & 1 & 0 & 0
\end{array}\right]
\end{aligned}
$$

where,

$$
k_{s}=\left(\frac{L_{d s}+L_{q s}}{2}\right)-\frac{\left(\frac{M_{d}+M_{q}}{2}\right)^{2}}{L_{r}}
$$

Moreover, based on equation (5), the matrices of $A_{2}, B_{2}$ and $C_{2}$ in equations (9) and (10) are obtained as (15a)$(15 \mathrm{c})$ :

$$
A_{2}=\left[\begin{array}{cccc}
1 & -\omega_{r} d t & 0 & 0 \\
\omega_{r} d t & 1 & 0 & 0 \\
0 & -\omega_{r} \frac{\left(M_{d}-M_{q}\right)}{2} d t & 1 & 0 \\
\omega_{r} \frac{\left(M_{d}-M_{q}\right)}{2} d t & 0 & 0 & 1
\end{array}\right]
$$




$$
\begin{aligned}
& B_{2}=\left[\begin{array}{llll}
0 & 0 & 0 & 0 \\
0 & 0 & 0 & 0
\end{array}\right]^{T} \\
& C_{2}=\left[\begin{array}{llll}
1 & 0 & 0 & 0 \\
0 & 1 & 0 & 0
\end{array}\right]
\end{aligned}
$$

Based on (14a)-(15c), two EKF algorithms can be used to estimate rotor fluxes in the RFOC (1) and RFOC (2). The block diagram of the flux observer based on EKF is shown in Figure 2. It can be noted that Figure 2 can be also used for healthy machine by only changing in the motor parameters as listed in Table 1 .

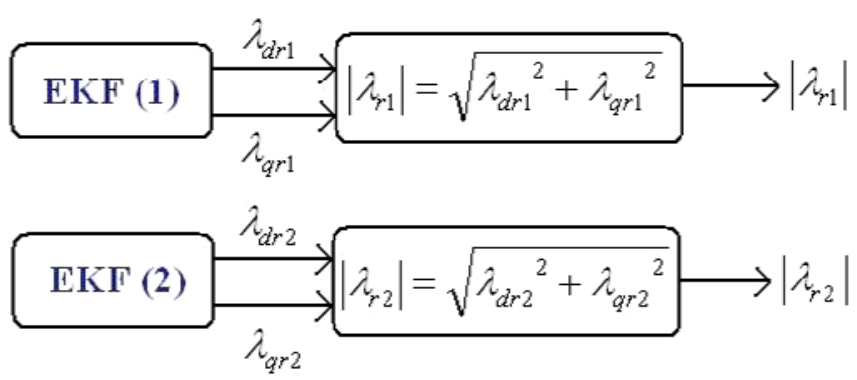

Figure 2. Block diagram of the flux observer based on EKF for high performance vector control of a faulty motor

This EKF algorithm is computed into three main steps as equations (16)-(18) [12]:

1-Prediction:

$$
\begin{aligned}
& x_{k}^{P}=A \hat{x}_{k-1} \mid B u_{k-1} \\
& P_{k}^{P}=A P_{k-1} A^{T}+Q
\end{aligned}
$$

2-Computation of Kalman Filter Gain:

$$
K_{k}=P_{k}^{P} C^{T}\left(C P_{k}^{P} C^{T}+R\right)^{-1}
$$

3-Update:

$$
\begin{aligned}
& \hat{x}_{k}=x_{k}^{P}+K_{k}\left(y_{k}-C x_{k}^{P}\right) \\
& \hat{P}=\left(1-K_{k} C\right) P_{k}^{P}
\end{aligned}
$$

where, $R$ and $Q$ are the covariance matrices of the noises.

\section{SIMULATION RESULTS}

In this section simulation results for a $475 \mathrm{~W}$ star-connected 3-phase IM is presented to validate the performance of the proposed strategy. The simulations are carried out based on Figure 1 and Figure 2 and using Matlab/M-File software. Runge-Kutta algorithm is considered to solve the healthy and faulty 3-phase IM equations. In the simulations the 3-phase IM is fed from a conventional SPWM VSI. For simplifying the simulations of the proposed method, the backward components in Figure 1 have been removed (As can be seen from equations (3)-(5), the stator voltage equations have extra terms due to the backward components. Since the backward components are proportional to the difference of the resistances, mutual and self inductances, it is possible to neglect them). In this work, it is assumed an immediate open-phase fault detection. The parameters of the simulated 3-phase IM are: 
$v=125 \mathrm{~V}, f=50 \mathrm{HZ}, P=4, r_{s}=20.6 \Omega, r_{r}=19.15 \Omega$

$L_{l s}=0.0814, L_{l r}=0.0814 \mathrm{H}, L_{m s}=0.851 \mathrm{H}$, power $=475 \mathrm{~W}$

Figure 3 shows the simulation results of the proposed method based on Figure 1 and Figure 2 for vector control of a healthy 3-phase IM. Figure 3 (a) shows the stator a-axis current, Figure 3 (b) shows the torque response and Figure 3 (c) shows the motor speed. In Figure 3, the reference speed and load are set to $300 \mathrm{rpm}$ and $0.5 \mathrm{~N} . \mathrm{m}$ respectively.

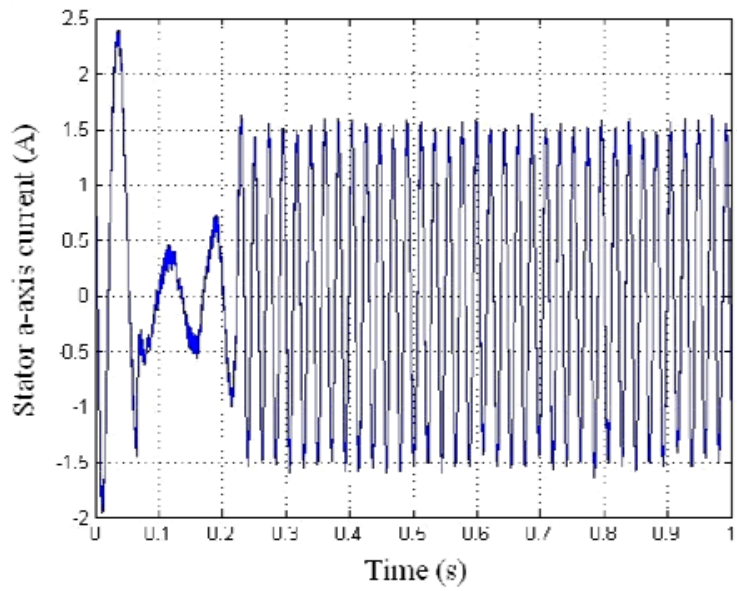

(a)

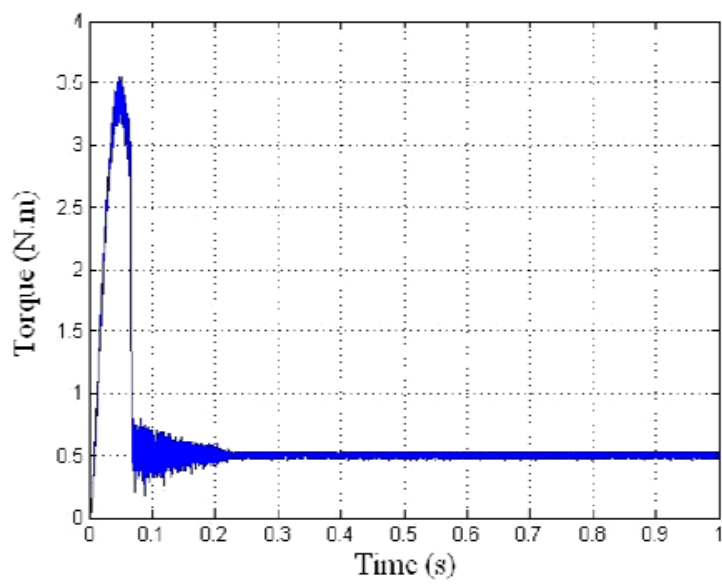

(b)

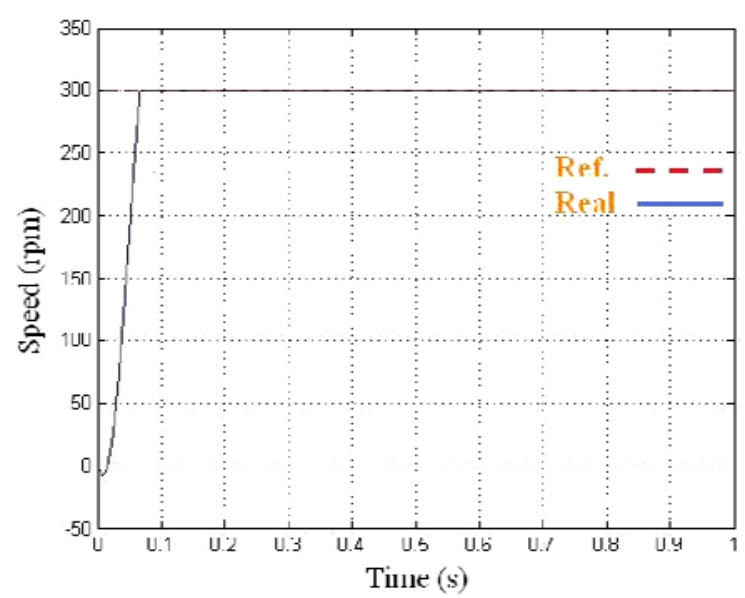

(c)

Figure 3. Simulation results of the proposed method for vector control of a healthy 3-phase IM; (a): Stator aaxis current, (b): Electromagnetic torque, (c): Speed

As can be seen from Figure 3, a sinusoidal form of the stator a-axis current is observed during operation of the motor. Moreover, the torque increases accordingly to the applied load. In this test, the real speed can follow the reference speed without any overshot and steady-state error. As mentioned before the structure of the presented controller (Figure 1) during normal condition is the same as basic RFOC method which is used for vector control of a healthy 3-phase IM.

Figure 4 shows the comparison between the basic and proposed methods for vector control of healthy and faulty 3-phase machines (Figure 3-left: basic controller and Figure 3-right: proposed controller based on Figure 1 and Figure 2). Figure 3 (a) shows the stator a-axis current, Figure 3 (b) shows the motor torque, Figure 3 (c) shows the estimated torque and Figure 3 (d) shows the motor speed. In Figure 3, the reference speed and load are set to 550rpm and 1N.m respectively. In Figure 4, it is supposed that an openphase fault is happened in phase " $\mathrm{c}$ " and at $\mathrm{t}=0.5 \mathrm{~s}$. 

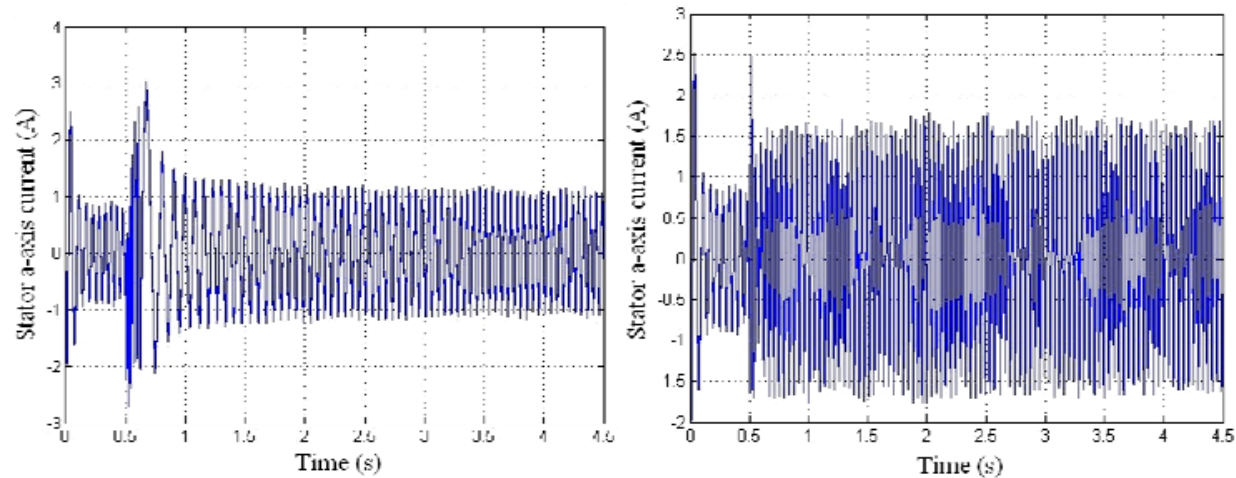

(a)
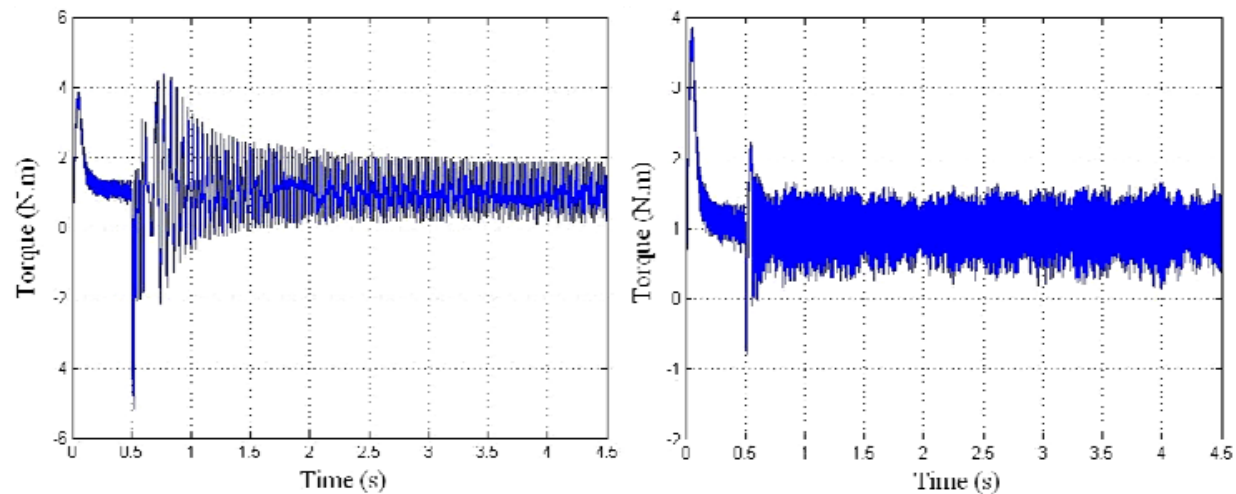

(b)
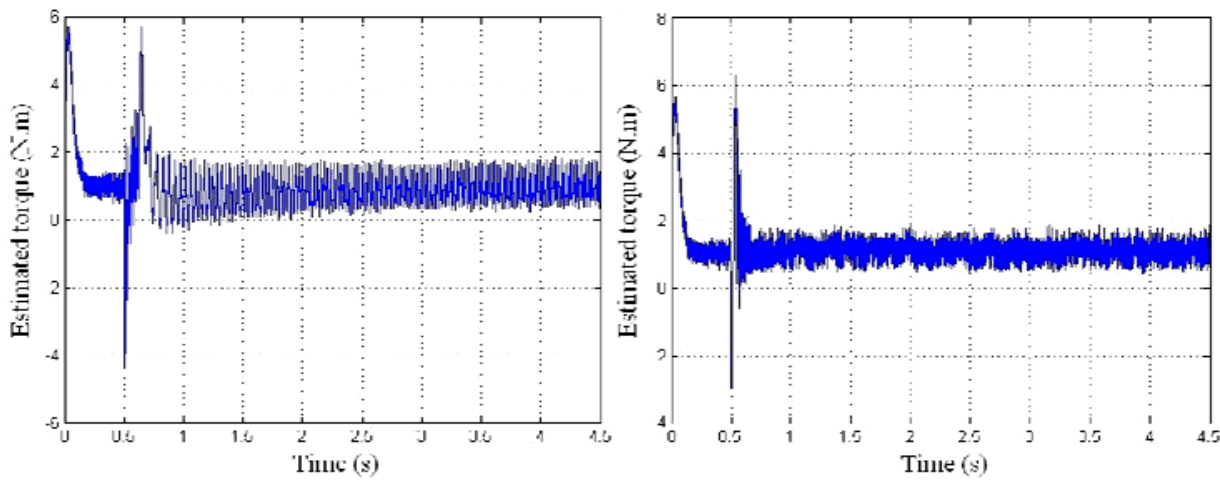

(c)
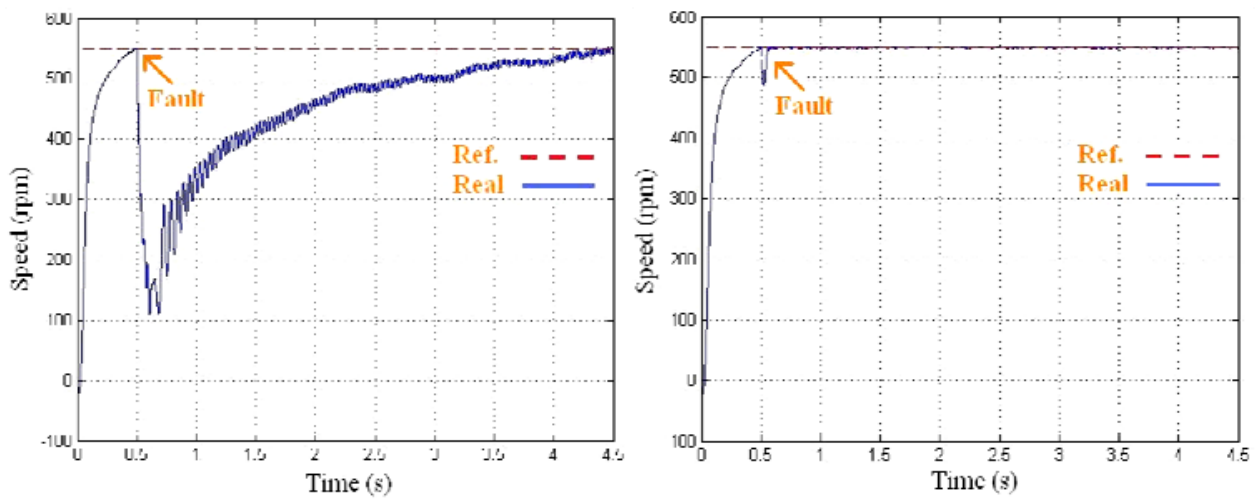

(d)

Figure 4. Simulation results of the basic (left) and proposed (right) methods for vector control of healthy and faulty 3-phase IMs; (a): Stator a-axis current, (b): Electromagnetic torque, (c): Estimated electromagnetic torque, (d): Speed 
Based on the presented results of the Figure 4, the basic RFO controller is unable to control the faulty 3-phase IM correctly (see Figure 4 (d)-left). It can be seen that in comparison with the basic controller, the performance of the proposed fault-tolerant strategy in both transient and steady-state conditions is good. As can be observed from Figure 4 (b), the proposed RFOC technique produces fewer ripples in the electromagnetic torque. Using basic controller, the peak to peak electromagnetic torque oscillation at steadystate is about $1.8 \mathrm{~N} . \mathrm{m}$ but by using proposed technique, the peak to peak electromagnetic torque oscillation reduced by about 1 N.m. Moreover, the estimated torque is obtained similar to the real IM torque (see Figure 4(c)-right). In the simulation results of Figure 4 (c)-right, the estimated torque is obtained from the estimated rotor flux. It can be concluded that the performance of the proposed observer to estimate the rotor flux in both normal and open-phase fault conditions is satisfactory.

Figure 5 shows the simulation results of the proposed method based on Figure 1 and Figure 2 for vector control of a 3-phase machine under open-phase fault condition. Figure 5 (a) shows the torque response of a faulty motor and Figure 5 (b) shows the motor speed of a faulty motor. In Figure 3, the reference speed and load are set to $1200 \mathrm{rpm}$ and 1 N.m respectively.

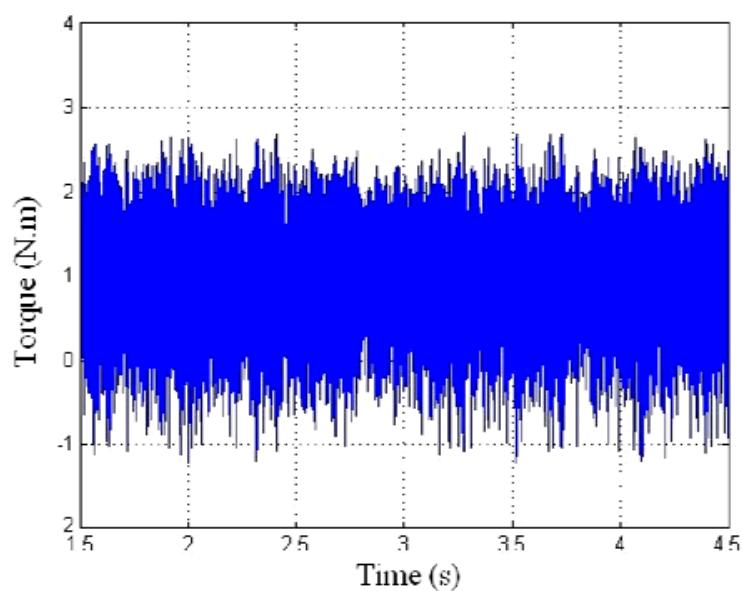

(a)

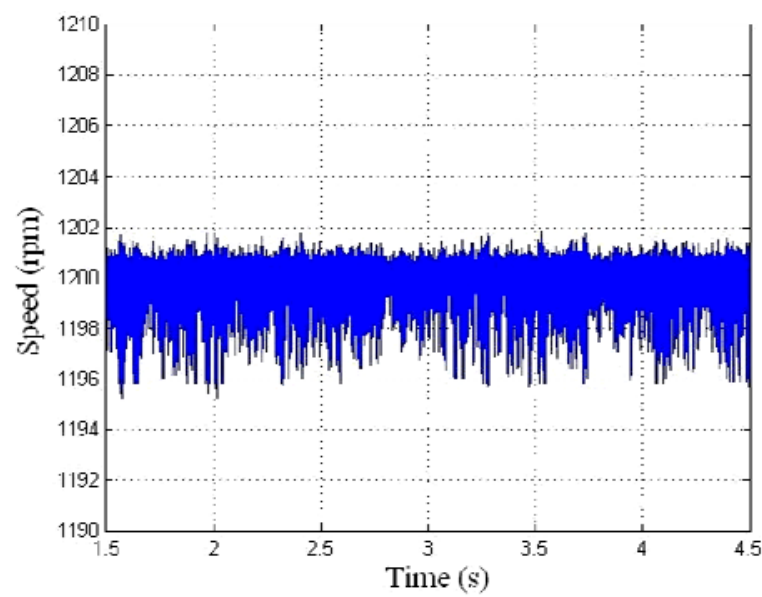

(b)

Figure 5. Simulation results of the proposed method for vector control of a faulty 3-phase IM; (a): Electromagnetic torque, (b): Speed

As can be seen from Figure 5, the torque increases accordingly to the applied load. In this test, the reference speed can also follow the reference speed without any steady-state error. Figure 5 shows the good performance of the proposed strategy for vector control of the faulty motor in the high speed and load condition.

\section{CONCLUSION}

In this paper, a novel high performance strategy to control star-connected 3-phase IM drives under open-phase fault based on IRFOC is proposed and simulated. To reduce the DC-offset problem with the basic IRFOC strategy, two modified EKF algorithms with two different stator currents (forward and backward stator currents) to estimate rotor flux are used. The proposed observer can be used for 3-phase IM drives during normal and open-phase fault conditions by only changing in the motor parameters. The results show the good performance of the proposed drive system for vector control of a faulty star-connected 3-phase IM.

\section{REFERENCES}

[1] M. Jannati, et al., "Modeling of Balanced and Unbalanced Three-Phase Induction Motor under Balanced and Unbalanced Supply Based on Winding Function Method", International Journal of Electrical and Computer Engineering (IJECE), vol. 5, pp. 644-655, 2015.

[2] A. Sayed-Ahmed and N.A. Demerdash, "Fault-Tolerant Operation of Delta-Connected Scalar- and VectorControlled AC Motor Drives", IEEE Transactions on Power Electronics, vol. 27, pp. 3041-3049, 2012.

[3] A. Saleh, et al., "Fault tolerant field oriented control of induction motor for loss of one inverter phase with restarting capability", In IEEE International Symposium on Industrial Electronics (ISIE 2007), pp. 1340-1345, 2007. 
[4] Y. Zhao and T.A. Lipo, "Modeling and control of a multi-phase induction machine with structural unbalance", IEEE Transactions on Energy Conversion, vol. 11, pp. 570-577, 1996.

[5] Z. Yifan and T.A. Lipo, "An approach to modeling and field-oriented control of a three phase induction machine with structural imbalance", In Proc. APEC, San Jose, TX, pp. 380-386, 1996.

[6] M. Jannati, et al., "Stator Field-Orientation Speed Control for 3-Phase Induction Motor under Open-Phase Fault", TELKOMNIKA (Telecommunication Computing Electronics and Control), vol. 13, pp. 432-441, 2015.

[7] M. Jannati, et al., "A simple vector control technique for 3-phase induction motor under open-phase fault based on GA for tuning of speed PI controller", In 2014 IEEE Conference on Energy Conversion (CENCON), pp. 213-218, 2014.

[8] B. Karanayil, et al., "Online stator and rotor resistance estimation scheme using artificial neural networks for vector controlled speed sensorless induction motor drive", IEEE Transactions on Industrial Electronics, vol. 54, pp. 167176, 2007.

[9] M. Barut, et al., "Switching EKF technique for rotor and stator resistance estimation in speed sensorless control of IMs", Energy Conversion and Management, vol. 48, pp. 3120-3134, 2007.

[10] E.S. De Santana, et al., "A predictive algorithm for controlling speed and rotor flux of induction motor", IEEE Transactions on Industrial Electronics, vol. 55, pp. 4398-4407, 2008.

[11] C. Patel, et al., "A rotor flux estimation during zero and active vector periods using current error space vector from a hysteresis controller for a sensorless vector control of IM drive", IEEE Transactions on Industrial Electronics, vol. 58, pp. 2334-2344, 2011.

[12] M. Barut, et al., "Real-time implementation of bi input-extended Kalman filter-based estimator for speed-sensorless control of induction motors", IEEE Transactions on Industrial Electronics, vol. 59, pp. 4197-4206, 2012.

[13] F.R. Salmasi and T.A. Najafabadi, "An adaptive observer with online rotor and stator resistance estimation for induction motors with one phase current sensor", IEEE Transactions on Energy Conversion, vol. 26, pp. 959-966, 2011 .

[14] T. Orlowska-Kowalska and M. Dybkowski, "Stator-current-based MRAS estimator for a wide range speedsensorless induction-motor drive", IEEE Transactions on Industrial Electronics, vol. 57, pp. 1296-1308, 2010.

[15] P. Vas, "Vector Control of AC Machines", Oxford science publication, 1990. 